Institute of $\mathbf{F}_{\text {ood and }} \mathbf{A}_{\text {gricultural }} \mathbf{S}_{\text {ciences }}$

\title{
Manuel de los Reglamentos del Agua de Florida: Leyes Federales y Agencias ${ }^{1}$
}

Michael T. Olexa, Laura Minton, Dulcy Miller, y Sarah Corbett ${ }^{2}$

\section{Agradecimientos}

Los autores agradecen a Richard Budell de la Oficina de Política del Agua Agrícola del Departamento de Agricultura y Servicios al Consumidor de Florida. Los autores también agradecen a David H. Hammonds, Consultor del Programa de Salud Ambiental, Oficina de Programas de Aguas de Drenaje en el Sitio, del Departamento de Salud de Florida, y a Edward A. Bettinger, Consultor del Programa de Salud Ambiental, Oficina de Programas de Agua del Departamento de Salud de Florida.

\section{Sinopsis}

La ley federal que existe respecto a la preservación de la calidad del agua es descrita en diferentes actas del Congreso. Estas actas así como las agencias responsables para su cumplimiento, son discutidas abajo.

\section{Sinopsis del Acta de Aguas Limpias}

El Acta de las Aguas Limpias esta dirigida a mantener y restaurar la integridad química, física y biológica de las aguas navegables, las cuales son ampliamente definidas como todas las aguas de los Estados Unidos. Estas incluyen:

- mares territoriales y los cuerpos mas grandes de agua.

1. Este es el documento EDIS FE065, una publicación del Department of Food and Resource Economics, Florida Cooperative Extension Service, Institute of Food and Agricultural Sciences, University of Florida, Gainesville, FL. Publicada Noviembre 2002. Por favor visite la página electrónica EDIS en http://edis.ifas.ufl.edu.

2. Michael T. Olexa, es profesor del Department of Food and Resource Economics, Florida Cooperative Extension Service, Institute of Food and Agricultural Sciences, University of Florida, Gainesville, FL; y miembro de Florida Bar; Presidente de Agricultural Law Committee of The Florida Bar; y Director del Agricultural Law Center. Laura Minton, Dulcy Miller, y Sarah Corbett son estudiantes graduadas de Levin College of Law, University of Florida, Gainesville, FL. Filiberto Reyes-Villanueva fue el traductor de la versión en ingles al español.

Esta publicación esta diseñada para proporcionar información precisa, actualizada y autorizada sobre esta material. Sin embargo, ya que las leyes, reglas administrativas y decisiones de la corte, sobre las cuales están basados, están sujetas a revisión constante; algunas partes de esta publicación podrían ser obsoletas en cualquier momento. Esta publicación es distribuida bajo el entendimiento que los autores no están involucrados en ninguna representación legal u otros servicios profesionales, y que la información contenida aquí no debe ser considerada como un substituto de una asesoria legal. Esta publicación no esta completa en proporcionar toda la información para lograr el cumplimiento de las leyes y reglamentos que gobiernan la protección del agua. Por estas razones, el uso de estos manuales por cualquier persona constituye un acuerdo para mantener libre de daño a los autores, al Florida Cooperative Extension Service, al Institute of Food and Agricultural Sciences, y a la University of Florida por cualquier demanda por responsabilidad de daños, o gastos en que pueda incurrir cualquier persona, como un resultado de hacer referencia o confianza sobre la información contenida en esta publicación. Esta publicación fue apoyada financieramente por el Florida Department of Agriculture and Consumer Services.

El Instituto de Alimentos y Ciencias Agrícolas es Un empleador que opera bajo Acción Afirmativa y provee Oportunidades Igualitarias, dedicado a promocionar la investigación, a información educativa y otros servicios, únicamente a los individuos e instituciones que operan baj discriminación sin considerar color, raza, sexo, edad, incapacidad u origen. Para más información sobre como obtener otras publicaciones de la extensión, comuníquese con la oficina de Servicio de Extensión de su condado. Servicio de Extensión de la Florida / Instituto de Alimentos y Ciencias Agrícolas / Universidad de la Florida / Christine Taylor Waddill, Decana. 
- lagos, arroyos, ríos, estanques y otros cuerpos pequeños de agua, si aun pueden remotamente afectar el comercio interestatal o a las personas involucradas en este.

- pantanos, definidos generalmente como tierras que son cubiertas periódicamente por agua suficiente para soportar vegetación, especialmente adaptada a este ambiente.

En primer lugar, a través de los requisitos que permiten sus descargas, el Acta de las Aguas Limpias, limita las cantidades de contaminantes que se pueden liberar en esta agua, en un intento por mantener un nivel seguro para la natación y otras actividades, así como también para los peces y la vida acuática.

\section{¿Quién Aplica el Acta de Aguas Limpias?}

El Acta de Aguas Limpias, en general, es aplicada por la Agencia de Protección Ambiental. (APA), pero el permiso de drenaje y relleno es exigido por el Cuerpo de Ingenieros del Ejercito. La APA ha establecido estándares nacionales para la cantidad máxima de contaminantes que pueden ser liberados bajo su permiso. Los estados están autorizados bajo el Acta para establecer sus propios estándares para niveles permisibles de contaminantes, tan estrictos como aquellos exigidos por la APA. Al estado también se le puede delegar la autorización de permisos por la APA. Actualmente a Florida se le ha delegado la aplicación de sólo partes del Acta (el Sistema Nacional de Eliminación de Descargas Contaminantes) porque aun es la APA quien emite los permisos.

\section{¿Cómo es Aplicada la Ley de Aguas Limpias?}

El Sistema Nacional de Eliminación de Descargas Contaminantes (SNEDC) es la vía principal para la aplicación del Acta. Estos permisos específicos son para:

- la cantidad y concentración de contaminantes que el responsable esta autorizado a descargar.
- programar la ejecución del cumplimiento.

- los requerimientos para la evaluación, y los reportes mensuales o tetramestrales que se tienen que presentar a la autoridad competente.

\section{¿Qué son las Fuentes de Punto y de No Punto?}

El Acta establece que tengan permiso todos los operadores de contaminación de fuentes de punto. Una "fuente de punto" es cualquier medio para transporte distinguible, confinado y medible, del cual un contaminante es o pueda ser descargado. Una fuente de punto puede ser un canal o un tubo para descarga de contaminantes, un recipiente que esta siendo lavado de contaminantes o cualquier otra fuente de la cual se liberen contaminantes dentro de un área especifica. Las descargas agrícolas de agua de lluvia y el flujo de retorno (también llamado "fuentes de no punto") de los sistemas de irrigación agrícola no son fuentes de punto, sin embargo, y por lo tanto no son cubiertos por el Acta (ver Glosario para definiciones de fuentes de no punto).

El SNEDC permite imponer dos tipos de limitaciones sobre los contaminadores de fuente de punto:

\section{Limitaciones de Descargas Basadas en}

Tecnología. Impone limites sobre los contenidos de desechos en base a la tecnología de tratamiento disponible.

\section{Limitaciones de Descargas Basadas en la} Calidad del Agua. Impone limites que dependen de los estándares establecidos para la calidad del cuerpo de agua (incluyendo cuerpos de agua del subsuelo) dentro de los cuales la descarga se lleva a cabo. Estos casos son vistos en base de caso por caso.

\section{¿Qué hay Acerca del Drenado y del Relleno?}

El Acta de Aguas Limpias requiere permisos separados para descarga de material para drenado y relleno en aguas navegables o pantanos. Los permisos para drenado y relleno son emitidos por los 
Cuerpos de Ingenieros del Ejercito, pero la APA tiene un poder de veto sobre estos. La APA puede hacer cumplir permisos emitidos por el Cuerpo o cuando fueron delegados a un estado.

\section{¿Qué hay Respecto al Petróleo y Substancias Peligrosas?}

El Acta también prohíbe descargas de petróleo o substancias especificas peligrosas. Además de eso, requiere que todos los derrames sean reportados inmediatamente si la cantidad derramada es mayor que la de las "cantidades reportables"individuales, las cuales la APA ha especificado para cada uno de las 300 "substancias dañinas" designadas. El reporte de derrames al Centro Nacional de Respuesta (ver Apéndice para números telefónicos) rápidamente protege al infractor de una acusación penal, pero no de una responsabilidad civil. También sirve para el desarrollo de un Plan Nacional de Contingencia para remover eficientemente los derrames.

\section{¿Cuáles son los Castigos?}

El grado de responsabilidad penal bajo el Acta depende primeramente de si el violador fue simplemente negligente (con multas de hasta $\$ 25,000$ por día y un año en prisión), si sabia de la violación ( $\$ 50,000$ por día y tres años en prisión), o si lo hizo sabiendo que pondría a otros en peligro inminente serio ( $\$ 250,000$ y 15 años en prisión). Todas estas multas pueden ser duplicadas por violaciones repetidas y algunas pueden ser mayores para las Empresas.

El Acta de Aguas Limpias también ejerce multas civiles y administrativas por cada violación del permiso del SNEDC. Las multas civiles pueden ser impuestas hasta por $\$ 25,000$ por día por cada violación. Las administrativas pueden ser de hasta $\$ 125,000$. La reparación de los daños (lo cual obliga a los infractores a cesar de contaminar) u otra compensación ordenada por la corte, también se pueden aplicar.

\section{Fuente}

Código 33 de los Estados Unidos secciones 1251 a 1387. 